\title{
Suicidal behavior in the community: Prevalence and factors associated with suicidal ideation
} Comportamento suicida na comunidade: prevalência
e fatores associados à ideação suicicla

\author{
Neury José Botega, ${ }^{1}$ Marilisa Berti de Azevedo Barros, ${ }^{2}$ \\ Helenice Bosco de Oliveira, ${ }^{2}$ Paulo Dalgalarrondo, ${ }^{1}$ \\ Letícia Marín-León ${ }^{2}$
}

Versão original aceita em Português

\begin{abstract}
Objectives: To estimate the life prevalence rates of suicidal ideation, suicidal plans and suicide attempts and verify factors associated to suicidal ideation. Methods: 515 individuals $\geq 14$ years old were selected at random (cluster and stratified sample) and assessed by means of the WHO SUPRE-MISS interview, SRQ-20 and AUDIT. Life prevalence rates were estimated. Uni and multivariate analyses were performed. Odds ratios, together with confidence intervals, were adjusted by gender and age. Results: Life prevalence rates were $17.1 \%(95 \% \mathrm{Cl}: 12.9-21.2)$ for suicidal ideation, $4.8 \%$ (95\% Cl: $2.8-6.8)$ for plans and 2.8\% (95\% Cl: 0.09 - 4.6) for suicide attempts. Only one-third of those who attempted suicide were later treated at a health facility. The 12-month prevalence rates were, respectively, 5.3\% (95\% Cl: $3.5-7.2), 1.9 \%(95 \% \mathrm{Cl}: 1.0-2.8)$ and $0.4 \%(95 \% \mathrm{Cl}:-0.3-1.1)$. Suicidal ideation was more frequently reported by women (OR = 1.7), young adults (20-29 years old: $O R=2.9 ; 30-39$ years old: $O R=3.6$, compared to the $14-19$ year old group), those living alone (OR $=4.2)$ and those presenting mental disorders (OR between 2.8 and 3.8). Conclusion: The prevalence of suicidal behavior was similar to that found in most studies carried out in other countries. Suicidal ideation was consistently associated with factors related to mental disorders or psychological distress. This should be taken into account when developing strategies to prevent suicidal behavior.
\end{abstract}

Keywords: Suicide, attempted, statistics \& numerical data; Self-Injurious behavior; Cross-sectional studies

\begin{abstract}
Resumo
Objetivos: Estimar a prevalência de ideação suicida (IS), planos e tentativas de suicídio (TS) ao longo da vida e identificar variáveis associadas à ideação suicida. Métodos: Foi realizado inquérito domiciliar com 515 indivíduos $\geq 14$ anos de idade, selecionados aleatoriamente, mediante amostragem estratificada, por conglomerados. Foram avaliados utilizando-se uma entrevista padronizada, da Organização Mundial de Saúde (OMS), sobre comportamento suicida (SUPRE-MISS), SRQ-20 e AUDIT. Foram calculadas as prevalências na vida e ajustados modelos de regressão logística uni e multivariada, calculando razões de chances $(R C)$, controlando-se sexo e idade como covariáveis, com seus respectivos intervalos de confiança (IC). Resultados: As prevalências foram de 17,1\% (IC 95\%: 12,9 - 21,2) para ideação suicida, 4,8\% (IC 95\%: 2,8 - 6,8) para planos e 2,8\% (IC 95\%: 0,09 - 4,6) para tentativas de suicídio. De cada três tentativas de suicídio, apenas uma chegou a ser atendida em um serviço médico. Ao longo dos últimos 12 meses, as prevalências foram, respectivamente, de 5,3\% (IC 95\%: 3,5 - 7,2), 1,9\% (IC 95\%: 1,0 - 2,8) e 0,4\% (IC 95\%: -0,3 - 1,1). A ideação suicida, ao longo da vida, foi mais freqüente entre mulheres $(R C=1,7)$, adultos jovens ( $R C$ 20-29 anos = 2,9; $R C$ 30-39 anos = 3,6, quando comparados com a faixa etária de 14-19 anos), entre os que vivem sozinhos ( $R C=4,2)$ e nos indivíduos que apresentaram indicadores de transtorno mental ( $R C$ entre 2,8 e 3,8). Conclusões: As prevalências não diferiram do observado pela maioria dos estudos realizados em outros países. A ideação suicida esteve consistentemente associada a indicadores de transtornos mentais ou de sofrimento psíquico. Essa observação, juntaente com o conhecimento dos fatores socioambientais associados ao comportamento suicida, deve ser levada em consideração na elaboração de estratégias de prevenção.
\end{abstract}

Descritores: Tentativa de suicídio / estatísticas \& dados numéricos; Conduta auto-lesiva; Estudos transversais

This study was conducted thanks to the financial grant received from the World Health Organization and from the Fundação de Apoio à Pesquisa do Estado de São Paulo (Foundation for the Support of Research in the State of São Paulo).

1 Department of Medical Psychology and Psychiatry of the Universidade Estadual de Campinas (SP) School of Medical Sciences

2 Department of Preventive and Social Medicine of the Universidade Estadual de Campinas (SP) School of Medical Sciences

\author{
Correspondence \\ Neury J Botega \\ FCM-UNICAMP, Departamento de Psiquiatria, Caixa Postal 6111 \\ 13081-970 Campinas, SP \\ Tel/fax: (19) 3788-7206 \\ E-mail: botega@fcm.unicamp.br
}

Financing: FAPESP nr. 02/08288-9.

Accepted: 09 November 2004 


\section{Introduction}

*This investigation is part of the Multisite Intervention Study on Suicidal Behaviors (SUPRE-MISS), of the World Health Organization (WHO). ${ }^{1}$ This is a transcultural project conducted in eight countries (Brazil, Estonia, India, Iran, China, South Africa, Sri Lanka and Vietnam) which is part of a WHO initiative focused on suicide prevention and under the scientific supervision of the Australian Institute for Suicide Research and Prevention of the Griffith University in Brisbane, Australia, as well as on the National Centre for Suicide Research and Prevention of Mental III-Health of the Karolinska Institute in Stockholm, Sweden. The SUPRE-MISS was devised in order to investigate suicidal behavior (through the use of populationbased surveys), as well as to develop methods for the study of such behavior and its course in different contexts, to evaluate treatment strategies for individuals who attempt suicide and to establish scientific bases for future international studies in this area.

Suicidal behavior is defined as an action through which an individual hurts himself (self-aggression), whatever the degree of lethal intention and recognition of the genuine reason for this action. Such a broad definition helps to conceptualize suicidal behavior through a continuum: starting with thoughts of self-destruction, extending to threats, suicidal gestures, suicide attempts and finally suicide. These behaviors together extend broadly and overlap. However, the most continuous and comprehensive data for the apprehension of epidemiological patterns have been derived from mortality statistics and were therefore restricted to suicide proper. ${ }^{2}$

Suicidal ideation has been studied in patient samples more often than in the general population, as have suicide attempts. However, $1.4 \%$ of the global burden caused by illnesses in the year 2002 was due to suicide attempts, and it is estimated that it will reach $2.4 \%$ in $2020 .{ }^{3}$ No Brazilian populationbased study has conducted an in-depth investigation into suicidal behavior. It is essential to understand the epidemiological pattern, which will provide observations and reflections to increase knowledge of the personal and sociocultural factors associated with suicidal behavior.

Two recent epidemiological studies ${ }^{4-5}$ demonstrated a correlation between suicidal ideation and suicide attempts. Pirkis et al investigated a sample of 10,641 subjects in Australia, $16 \%$ of which had experienced suicidal ideation. In this subgroup, $12 \%$ attempted suicide during a one-year follow-up period. ${ }^{4}$ In Baltimore, Kuo et al conducted a prospective cohort study of 3,481 subjects for a period of 13 years. Individuals who presented suicidal ideation at the beginning of the study were at a six-times greater risk for attempting suicide in the following 13 years. ${ }^{5}$ Therefore, we may assume that experiencing suicidal ideation represents an elevated risk of attempting suicide at some point in the future. Suicide attempts, however, represent the principal risk of successful suicide in the future. ${ }^{6}$

In addition to what was reported above, the thorough study of individuals who present suicidal ideation in the community is justified, since these individuals clearly make greater use of outpatient services and hospitalization in mental and general health facilities. ${ }^{7-8}$ Furthermore, such a subgroup, in addition to seeking and using medical attention at such facilities more frequently, needs additional medication, counseling and information. However, the same subgroup feels these needs are not adequately met.

This study aimed to estimate the prevalence rate of suicidal behavior (ideation, plans and attempts) in the city of Campinas and to determine which variables are directly associated with suicidal ideation.

\section{Methods}

\section{Subjects}

In 2003, the population of Campinas was estimated to be one million inhabitants (98\% living in the urban area and $78 \%$ over the age of 14). In this study, the population evaluated consisted of individuals older than 14 who were not institutionalized and who resided in the urban zone of the municipality.

\section{Size of the sample}

In order to calculate the size of the sample, the lifetime prevalence of suicide attempts in the general population was considered to be $2.7 \%$ (proportions published in the literature are found to be between $1.8 \%$ and $3.6 \%$ ). The minimum size defined for the sample was 500 individuals, considering a $2 \%$ sample error, a 95\% confidence level and a design effect of 2.

\section{Sample strategy}

Cluster and stratified sampling was used in three stages: the primary sample unit was the census sector; the sample unit of the second stage was the residence and the sample unit of the third stage was the individual.

The registry of residences and census sectors of the Inquérito de Saúde no Estado de São Paulo (ISA-SP, Health Survey of the State of São Paulo) ${ }^{10}$ was used in this study. The census sectors in Campinas were grouped into three strata, according to the percentage of heads of household who had attended university: stratum A (more than 25\%; total of 278 sectors); stratum B (from 5 to $25 \%$, comprising 252 sectors); stratum C (less than 5\%, 305 sectors). Ten sectors in each stratum were selected at random. The selected sectors were subjected to field research, which made the rounds of all existing residences based on the outline sketches of the blocks supplied by the Instituto Brasileiro de Geografia e Estatística (IBGE, Brazilian Institute of Geography and Statistics).

For this study, 20 residences in each census sector were randomly selected through systematic sampling of the addresses registered in the list. This procedure resulted in 200 residences per stratum, comprising 600 residences. Finally, during fieldwork, an individual aged 14 or over was randomly selected from each residence (through sequential and continuous counting of the residents arranged in increasing order by age until a random number, previously defined and printed on the cover of the form, was reached).

\section{Instrument}

The instrument applied was based on the European Parasuicide Study Interview Schedule (EPSIS), used in the WHO/EURO Multicentre Study on Suicide Behaviour. ${ }^{11}$ The final version devised by the principal SUPRE-MISS researchers, consists of the following sections: sociodemographic information, history of personal suicidal

NOTE: *Bertolote JM, Fleischmann A, De Leo D, Wasserman D, Bolhari J, Botega NJ, et al. Suicide attempts, plans, and ideation in culturally diverse sites: the WHO SUPRE-MISS community survey. Br Med J. (submitted). 
behavior and suicidal behavior within the family, opinion regarding community problems, mental and physical health, contact with health centers and questions related to the use of alcohol and drugs. ${ }^{* *}$

Suicidal behavior was evaluated using the following keyquestions: "Have you ever seriously thought of putting an end to your life?", "Have you ever made a plan to do this?", "Have you ever attempted suicide?" Additional information was collected in case the person gave an affirmative answer to any of these questions.

Two psychometric scales were inserted in the local protocol: the Self-Reporting Questionnaire (SRQ-20) and the Alcohol Use Disorder Identification Test (AUDIT), both validated for use in Brazil. The SRQ-20 contains 20 yes/no questions that track non-psychotic psychiatric morbidity. ${ }^{12}$ Scores equal to or higher than 8 , on a 0 to 20 scale were used as indicators of psychiatric morbidity. The AUDIT identifies alcohol users who are within the risk range. ${ }^{14} \mathrm{~A}$ score equal to or higher than 8 (variation, $0-40$ ) is suggestive of abusive use of alcohol or alcohol dependence. ${ }^{15}$

\section{Procedures}

Twelve interviewers (five medical students, two nurses, three psychologists, two nutritionists) were trained. The training consisted of three 90-minute sessions and focused on protocol details and interview technique. Prior to the principal study, each interviewer applied the instrument to two people, which served as a basis for clarifying how to fill out the forms, as well as improving the instrument language and format.

The researchers made up to three attempts to interview the person who had been selected, in case the person was not at home. All interviews were made with no participation by third parties. Residential zones which were considered dangerous were visited by groups of interviewers, with the support of a university vehicle. The interview was reapplied to 50 randomly selected individuals with the objective of checking the reliability of the data supplied. Field research was initiated on May 7, 2003 and ended on July 15, 2003. All participants gave written informed consent. The confidentiality of the information was assured. This study was approved by the Ethics Research Committee of the FCM-UNICAMP.

\section{Statistical analysis}

The prevalence of suicidal behavior (ideation, plans and attempts), both lifetime and within the last 12 months, was calculated. Univariate analysis was used to compare lifetime prevalence of suicidal ideation in the subcategories of each variable. For prevalences and for odds ratios (OR), we calculated confidence intervals of $95 \%$ adjusted for gender and age. A multiple logistic regression was conducted, and variables presenting a $p<0.20$ in the univariate analysis were included in the final model. All analyses were evaluated with the aim of compensating for the different selection probabilities of the individuals in the sample. In each stratum, the weight of an individual selected in a given residence of a particular census sector was the opposite of the selection probability for that individual. All statistic calculations were performed using the Stata program, version 7.0.

\section{Results}

A total of 538 individuals were approached. Of these, 23 ( $4.2 \%$ of the total) refused to participate, resulting in a final total of 515 interviews. The number of refusals was higher in stratum $A$, followed by $B$ and $C(17,5$ and 1 , respectively).

Lifetime prevalence rates were $17.1 \%$ (95\% Cl: $12.9-21.2)$ for suicidal ideation, $4.8 \%(95 \% \mathrm{Cl}: 2.8-6.8)$ for plans and $2.8 \%(95 \% \mathrm{Cl}: 0.9-4.6)$ for suicide attempts. Only onethird of those who attempted suicide were later treated at a health care facility. The prevalence within the last 12 months was $5.3 \%(95 \% \mathrm{Cl}: 3.5-7.2)$ for suicidal ideation, $1.9 \%$ $(95 \% \mathrm{Cl}: 1.0-2.8)$ for plans and $0.4 \%(95 \% \mathrm{Cl}:-0.3-1.1)$ for suicide attempts.

Lifetime prevalence rates for suicidal ideation were higher among women, young adults and those living alone (Table 1). This was apparently independent of marital and parental status (Table 2). The prevalence rate for suicidal ideation was higher among individuals presenting indicators of mental disorder (Table 3). This was the most relevant finding in the logistic regression (Table 4 ).

\section{Discussion}

This article is the first communication that provides local results, derived from the WHO SUPRE-MISS protocol, in which we used an instrument translated and adapted to different cultural contexts to evaluate suicidal behavior. As far as we know, this is the first population-based study on suicidal behavior conducted in Brazil.

In approximate numbers, for every 17 people who have "seriously thought about putting an end to their lives", five actually planned the suicide act, three effectively attempted suicide and, of these three, only one later received medical attention. Keeping future prevention strategies in mind, it is essential to collect information on suicidal behavior directly in the community, taking into account the reach of such behavior. We may, therefore, learn a bit more about the "submersed portion" of the iceberg, which represents a range of behaviors not registered by health care facilities.

A number of methodological limitations should be considered. Although the total number of interviews was adjusted to the sample size required for prevalence rates, the number of individuals was small in some response categories. This limits the interpretation of some results and type 2 errors may occur. However, multiple comparisons using exploratory univariate analysis might have increased the probability of type 1 errors.

The $17.1 \%$ and $2.7 \%$ prevalence rates for suicidal ideation and suicide attempts, respectively, are similar to those encountered in other studies (conducted mainly in Europe, USA and Australia), in which life prevalence rates for suicidal ideation fell between 10 and $28 \%$, and those of suicide attempts between $3 \%$ and $5 \% .{ }^{16}$

Weissman et al ${ }^{16}$ reviewed nine community epidemiological studies conducted in socially heterogeneous countries (USA, Canada, Puerto Rico, France, Germany, New Zealand, Lebanon, Taiwan and South Korea). All studies included in

NOTE: ** In order to collect census information, The Instituto Brasileiro de Geografia e Estatística (IBGE, Brazilian Institute of Geography and Statistics) divides cities into census sectors, each one a basic collection unit consisting of a contiguous territorial area situated in a single block (urban, rural or isolated urban) as defined by city law. An urban census sector consists of an average of 300 residences, and a rural census sector comprises an average of 200 residences. 
Table 1 - Prevalence of suicidal ideation by sociodemographic variable; SUPRE-MISS, Campinas, 2003

\begin{tabular}{|c|c|c|c|c|c|}
\hline \multirow[t]{2}{*}{ Variable and category } & \multirow[t]{2}{*}{ Number of individuals } & \multicolumn{2}{|c|}{$\begin{array}{l}\text { Lifetime prevalence of suicidal } \\
\text { ideation }\end{array}$} & \multirow[t]{2}{*}{ Odds ratio ${ }^{\#}$} & \multirow[t]{2}{*}{$95 \% \mathrm{Cl}$ of odds ratio } \\
\hline & & $\%$ & $95 \% \mathrm{Cl}$ & & \\
\hline \multicolumn{6}{|l|}{ Gender } \\
\hline Male & 199 & 13.3 & $8.4-18.2$ & 1 & - \\
\hline Female & 316 & 20.6 & $15.9-25.3$ & $1.7^{\star}$ & $1.1-2.5$ \\
\hline TOTAL. & 515 & 17.1 & $12.9-21.2$ & - & - \\
\hline \multicolumn{6}{|l|}{ Age bracket (years) } \\
\hline $14-19$ & 54 & 8.3 & $1.3-15.3$ & 1 & - \\
\hline $20-29$ & 103 & 20.8 & $11.7-29.9$ & $2.9^{\star \star \star \star \star}$ & $0.933-8.9$ \\
\hline $30-39$ & 98 & 24.9 & $12.1-37.6$ & $3.6^{* *}$ & $1.2-11.2$ \\
\hline $40-49$ & 96 & 17.7 & $9.7-25.8$ & 2.3 & $0.7-7.3$ \\
\hline $50-59$ & 71 & 14.6 & $5.9-23.3$ & 1.9 & $0.5-6.5$ \\
\hline$\geq 60$ & 93 & 10.4 & $3.5-17.3$ & 1.2 & $0.5-3$ \\
\hline \multicolumn{6}{|l|}{ Occupation } \\
\hline Working full time & 207 & 16.4 & $11.22-21.6$ & 1 & - \\
\hline Working part time & 46 & 29.9 & $15.3-44.5$ & $1.9^{* \star \star \star *}$ & $0.9-3.9$ \\
\hline Unemployed & 32 & 18.9 & $5.4-32.5$ & 1.2 & $0.5-2.9$ \\
\hline Student & 47 & 14.8 & $4.6-25$ & 0.8 & $0.3-2$ \\
\hline On disability & 10 & 12.9 & $9.0-34.9$ & 0.7 & $0.1-5.5$ \\
\hline Retired & 59 & 9.8 & $2.3-17.2$ & 0.5 & $0.2-1.6$ \\
\hline Housewife & 98 & 18 & $9.9-26.1$ & 0.8 & $0.4-1.7$ \\
\hline Other & 20 & 13.2 & $0.9-27.4$ & 0.7 & $0.2-2.8$ \\
\hline \multicolumn{6}{|l|}{ Income (US\$) } \\
\hline None & 127 & 17.4 & $11.1-23.6$ & 1 & - \\
\hline $1-2500$ & 188 & 16.5 & $10.7-22.4$ & 1.1 & $0.6-2$ \\
\hline $2501-10,000$ & 146 & 15.0 & $8.2-21.8$ & 1.1 & $0.5-2.3$ \\
\hline$\geq 10,001$ & 54 & 25.2 & $3.7-46.8$ & 2.1 & $0.6-7.2$ \\
\hline \multicolumn{6}{|l|}{ Schooling (years) } \\
\hline $0-3$ & 68 & 9.6 & $2.3-16.8$ & 1 & - \\
\hline $4-8$ & 215 & 16.4 & $10.7-22.2$ & 1.9 & $0.6-5.4$ \\
\hline $9-11$ & 156 & 21.7 & $13.6-29.8$ & $2.7^{* * *}$ & $0.9-8.2$ \\
\hline 12 or more & 75 & 15.7 & $0.01-31.5$ & 1.8 & $0.4-7.9$ \\
\hline
\end{tabular}

$95 \% \mathrm{Cl}: 95 \%$ confidence interval

\# Odds ratio adjusted for gender and age

${ }^{*} p=0.009$

$* * p=0.02$

$* * x=0.05$

$* * * 0.06$ 
Table 2 - Prevalence of suicidal ideation by characteristics of family and religion; SUPRE-MISS, Campinas, 2003

\begin{tabular}{|c|c|c|c|c|c|}
\hline \multirow[t]{2}{*}{ Variable and category } & \multirow[t]{2}{*}{$\begin{array}{l}\text { Number of } \\
\text { individuals }\end{array}$} & \multicolumn{2}{|c|}{$\begin{array}{c}\text { Lifetime prevalence of suicidal } \\
\text { ideation }\end{array}$} & \multirow[t]{2}{*}{ Odds ratio* } & \multirow[t]{2}{*}{$\begin{array}{l}95 \% \mathrm{Cl} \text { of odds } \\
\text { ratio }\end{array}$} \\
\hline & & $\%$ & $95 \% \mathrm{Cl}$ & & \\
\hline \multicolumn{6}{|l|}{ Marital status } \\
\hline Single & 148 & 18.9 & $10.9-26.9$ & 1 & - \\
\hline Married/steady partner & 286 & 15.5 & $10.6-20.4$ & 0.7 & $0.3-1.6$ \\
\hline Widowed/divorced & 81 & 18.7 & $7.4-30$ & 0.8 & $0.2-3.4$ \\
\hline \multicolumn{6}{|l|}{ Conjugal separations } \\
\hline No & 428 & 16.5 & $11.5-21.5$ & 1 & \\
\hline Yes & 87 & 20.2 & $9.2-31.2$ & 1.3 & $0.6-3$ \\
\hline \multicolumn{6}{|l|}{ Lives with: } \\
\hline Children (offspring) only & 43 & 9.4 & $1.5-17.2$ & 1 & - \\
\hline $\begin{array}{l}\text { Partner (with or without } \\
\text { children), or with parents }\end{array}$ & 386 & 16.2 & $11.7-20.7$ & $2.2^{*}$ & $0.9-5.6$ \\
\hline $\begin{array}{l}\text { Alone, or with other } \\
\text { relatives/friends }\end{array}$ & 86 & 26.6 & $16.5-36.6$ & $4.2^{* *}$ & $1.6-10.8$ \\
\hline \multicolumn{6}{|l|}{ Has children } \\
\hline No & 160 & 17.5 & $9.7-25.4$ & 1 & \\
\hline Yes & 355 & 16.8 & $11.0-21.6$ & 1 & $0.4-2.3$ \\
\hline \multicolumn{6}{|l|}{$\begin{array}{l}\text { Responsible for a child } \\
\text { younger than } 16\end{array}$} \\
\hline No & 322 & 16.9 & $11.6-22.2$ & 1 & - \\
\hline Yes & 193 & 17.4 & $11.3-23.4$ & 1 & $0.6-1.8$ \\
\hline \multicolumn{6}{|l|}{ Religion } \\
\hline Protestant & 100 & 14.4 & $13.4-33.3$ & 1 & - \\
\hline Catholic & 345 & 23.4 & $9.7-19.1$ & 1.7 & $0.8-3.9$ \\
\hline Spiritualist & 22 & 33.7 & $11.4-56.0$ & $2.7^{* * *}$ & $0.9-7.5$ \\
\hline None & 41 & 14 & $1.8-26.3$ & 1 & $0.3-2.6$ \\
\hline \multicolumn{6}{|l|}{ Goes to church: } \\
\hline Once a week & 218 & 18.7 & $13.7-23.7$ & 1 & - \\
\hline Once a month & 113 & 17.1 & $9.1-25.2$ & 0.9 & $0.5-1.7$ \\
\hline Less & 143 & 16.5 & $8.9-24.1$ & 0.9 & $0.4-1.7$ \\
\hline \multicolumn{6}{|l|}{$\begin{array}{l}\text { Considers } \\
\text { himself/herself religious }\end{array}$} \\
\hline No & 47 & 19.3 & $7.6-30.9$ & 1 & - \\
\hline Yes & 466 & 16.6 & $12.0-21.3$ & 0.8 & $0.3-1.9$ \\
\hline $\begin{array}{l}95 \% \mathrm{Cl}: 95 \% \text { confidence in } \\
\# \mathrm{Odds} \text { ratio adjusted for ge } \\
{ }^{*} p=0.08 \\
{ }^{* * *} p=0.005 \\
{ }^{* *} p=0.05\end{array}$ & age & & & & \\
\hline
\end{tabular}


Table 3 - Prevalence of suicidal ideation by mental health and health-related behavior; SUPRE-MISS, Campinas, 2003

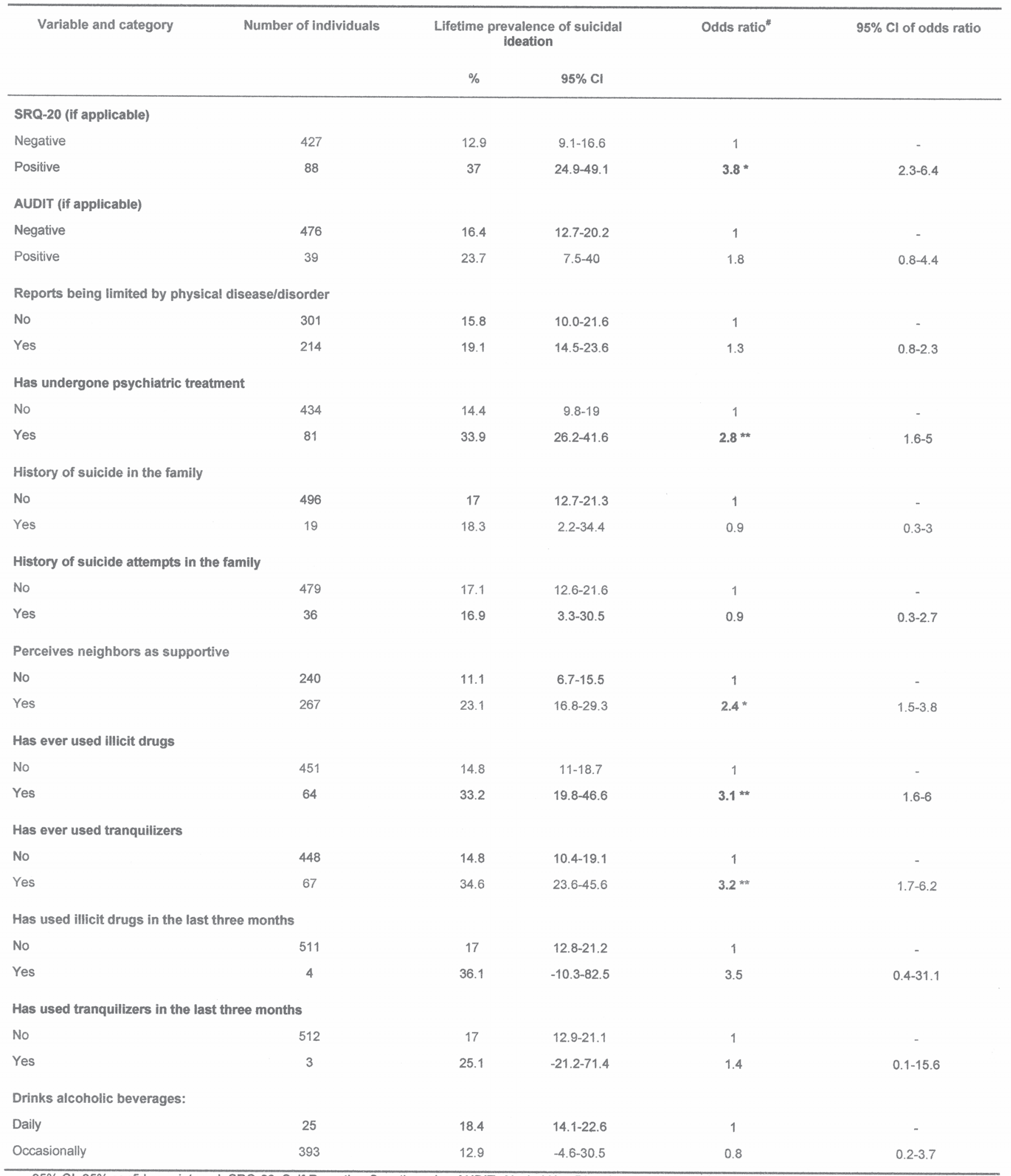

$95 \% \mathrm{Cl}: 95 \%$ confidence interval; SRQ-20: Self-Reporting Questionnaire; AUDIT: Alcohol Use Disorder Identification Test \#Odds ratio adjusted for gender and age 
Table 4 - Factors correlated with lifetime suicidal ideation: variables that were included in the multivariate logistic regression model SUPRE-MISS, Campinas, 2003

\begin{tabular}{|c|c|c|c|c|c|c|}
\hline \multirow[t]{2}{*}{ Variable and category } & \multicolumn{3}{|c|}{ Unadjusted OR } & \multicolumn{3}{|c|}{ Adjusted OR } \\
\hline & OR & $95 \% \mathrm{Cl}$ & $p$ & OR & $95 \% \mathrm{CI}$ & $\boldsymbol{p}$ \\
\hline \multicolumn{7}{|l|}{ Gender } \\
\hline Male & 1 & & & 1 & & \\
\hline Female & 1.7 & $1.1-2.5$ & 0.009 & 1.4 & $0.9-2.2$ & 0.06 \\
\hline \multicolumn{7}{|l|}{ Age bracket } \\
\hline $14-19$ & 1 & & & 1 & & \\
\hline $20-59$ & 2.7 & $0.9-7.7$ & 0.05 & 3.1 & $0.9-9.9$ & 0.05 \\
\hline$\geq 60$ & 1.3 & $0.5-3$ & 0.5 & 1.4 & $0.5-3.4$ & 0.4 \\
\hline \multicolumn{7}{|l|}{ Lives with: } \\
\hline Children (offspring) only & 1 & & & 1 & & \\
\hline $\begin{array}{l}\text { Partner (with or without children), or } \\
\text { with parents }\end{array}$ & 1.8 & $0.7-4.8$ & 0.2 & 2.7 & $0.9-8.4$ & 0.07 \\
\hline Alone, or with other relatives/friends & 3.5 & $1.3-9.2$ & 0.01 & 4.3 & $1.3-13.8$ & 0.01 \\
\hline \multicolumn{7}{|l|}{ SRQ-20 (if applicable) } \\
\hline Negative & 1 & & & 1 & & \\
\hline Positive & 3.9 & $2.4-6.5$ & 0.0001 & 3.2 & $1.9-5.3$ & 0.0001 \\
\hline \multicolumn{7}{|l|}{ Has undergone psychiatric treatment } \\
\hline No & 1 & & & 1 & & \\
\hline Yes & 3 & $1.7-5.3$ & 0.0001 & 2.5 & $1.3-5$ & 0.009 \\
\hline \multicolumn{7}{|l|}{ Perceives neighbors as supportive } \\
\hline No & 1 & & & 1 & & \\
\hline Yes & 2.4 & $1.4-3.9$ & 0.001 & 2.3 & $1.4-3.9$ & 0.002 \\
\hline \multicolumn{7}{|l|}{ Has ever used illicit drugs } \\
\hline No & 1 & & & 1 & & \\
\hline Yes & 2.8 & $1.5-5.3$ & 0.002 & 2.2 & $1-4.5$ & 0.03 \\
\hline
\end{tabular}

this reanalysis used the same suicidal ideation standardization method (questions from the Diagnostic Interview Schedule). In total, the studies comprised 40 thousand subjects. We found lifetime prevalence rates for suicidal ideation ranging from $2.1 \%$ (in Beirut, Lebanon) to $18.5 \%$ (in Christchurch, New Zealand). The authors attempted to explain such disparate values based on possible social and cultural differences, both in the sense of admitting to having had suicidal ideation and in the sense of actually having them.

The value of $17.1 \%$ found in the present study for lifetime suicidal ideation is situated in the upper range in relation to the body of international studies. This high value may result from:

1) Greater willingness to recognize suicidal ideation due to way in which we formulated the question (Have you ever thought about putting an end to your life?", rather than using the word "suicide") in the interview (as is the case of the Diagnostic Interview Schedule). By avoiding the taboo word, we may have favored acceptance, recognition and the affirmative answer.

2) Truly high values for suicidal ideation, accompanied by mental suffering, in the population studied - within a sociocultural context of stresses related to increasing urban violence, economic recession and poor medical and social services.

Among the sociodemographic and clinical factors associated with suicidal ideation, international studies generally emphasize the following: being female, having a psychiatric disorder (depression, anxiety, etc.), abusing or being dependent on alcohol or drugs, not having a steady partner (being divorced, separated or single), ${ }^{16}$ and being in an unfavorable professional situation, such as being unemployed or underqualified. ${ }^{17}$

Regarding gender, we found suicidal ideation to be more common among women. Reports in the literature show that women tend to present more lifetime suicidal ideation. ${ }^{16}$ However, Renberg ${ }^{18}$ found no gender-related differences among Swedes, and Hintikka ${ }^{19}$ reported a higher prevalence of suicidal ideation among men in Finland. Therefore, despite the fact that women present a higher prevalence of suicidal ideation in the majority of contexts studied, sociocultural differences appear to be important as well.

In analyzing responses given by individuals in the various age brackets, we observed higher lifetime prevalence of suicidal ideation among young adults (aged 20-39). Although we do 
not have sufficient data to explain this finding unequivocally, this may also reflect a recent shift in suicidal behavior among young people, ${ }^{20}$ similar to that of a memory bias, in which the elderly remember less or ponder less emphatically the feelings they held in their youth regarding life and death.

We did not find a correlation between marital status and suicidal ideation. However, living alone or with friends and relatives other than parents and children, did correlate significantly with frequency of suicidal ideation, which was higher among such individuals than among those living only with their children. This finding may, at least in part, be related to the sense of responsibility one has to raise the children, even when no longer residing with the partner. This circumstance may act as a protective factor against suicidal behavior.

There is the perception that being religious may be protective against suicidal behavior. It is notable that, in comparison to Protestants, a greater proportion of Spiritualists reported suicidal ideation. Kardecist Spiritualism is one of the denominations that most strongly and explicitly condemn suicide. The canonical books of Spiritualism provide at least 26 citations condemning suicide and 8 condemning suicidal behavior. In Spiritualism, suicide "... is the most serious crime against the self and against God (...) the beginning of the greatest torment that the human creature can suffer." 21 However, Protestantism (Pentecostal or traditional) also condemns suicide and lays down a strict moral code for controlling the thoughts and behavior of the faithful. ${ }^{22}$ This seems to indicate that a strict and penetrating moral code has a greater effect on the development and expression of suicidal thoughts that does a canonical prohibition against suicide. In fact, such a possibility is consistent with the Durkheimian hypothesis that it is the integrating and coercive nature of the group, and not necessarily theological condemnation, that is protective against suicide.

The perception that the community in which one lives is unsupportive was found to correlate with suicidal ideation. This brings us back to the probable protective effect of a social support network (family, friends, colleagues and fellow church goers), as well as to the question of how the established relationships that surround an individual experiencing suicidal ideation are perceived by that individual. ${ }^{23}$

We found no correlation between unemployment and suicidal ideation, and the finding that suicidal ideation is more common among individuals working part time is difficult to interpret. Such a relationship is probably linked to a third, uninvestigated, factor.

In general, our findings confirm the notion that suicidal ideation is consistently correlated with indicators of mental disorder or psychological distress. ${ }^{24}$ This was evidenced by the results obtained using an instrument (the SRQ-20) that evaluates nonpsychotic psychiatric morbidity as well as that seen among those having undergone psychiatric and psychotropic treatment or having used illicit drugs. Despite the fact that lifetime frequency of suicidal ideation was higher among those who imbibed in alcoholic beverages more often or inappropriately (AUDIT), this variable did not present a statistically significant difference.

This study focused on suicidal ideation and factors associated with suicidal ideation. However, it is of note that one cannot easily link suicidal ideation to effective suicide attempts. As we have seen, over the course of a lifetime, suicidal thoughts are six times more frequent than actual suicide attempts, although the frequency of planning how to take one's own life is much nearer to that of the attempt (a ratio of approximately $5: 3)$. This observation, together with the knowledge of the factors most closely related to suicidal behavior, may inform decisions regarding the adoption of prevention strategies. Certainly, the evaluation of the data collected by the SUPREMISS in various cultures worldwide will be able to provide some answers that could not be clarified in this populational study of a single city.

\section{Conclusion}

In the present study, the observed prevalence of suicidal behavior, evaluated in terms of ideation, planning and suicide attempts, is in agreement with that reported in the majority of studies conducted in other countries. The higher frequency of suicidal ideation among Kardecist Spiritualists is a finding which merits further investigation. Due to the strong correlation between suicidal ideation and indicators of mental disorder, we recommend that clinical treatment of individuals with compromised mental health include careful investigation of suicidal ideation and suicide planning.

\section{Acknowledgments}

This study was funded by grants from the World Health Organization and from the Fundação de Apoio à Pesquisa do Estado de São Paulo (Foundation for the Support of Research in the State of São Paulo). The authors are grateful to for the statistical guidance provided by Maria Cecília Góes Porto

\section{References}

1. World Health Organization. Multisite intervention study on suicidal behaviours: SUPRE-MISS: Protocol of SUPRE-MISS. Geneva: WHO; 2002.

2. Werlang B, Botega NJ, editors. Comportamento suicida. Porto Alegre: Artmed; 2004.

3. World Health Organization. Shaping the future. The World Health Report 2003. Geneva: WHO; 2003.

4. Pirkis J, Burgess P, Dunt D. Suicidal ideation and suicide attempts among Australian adults. Crisis. 2000;21(1):16-25.

5. Kuo WH, Gallo JJ, Tien AY. Incidence of suicide ideation and attempts in adults: the 13-year follow-up of a community sample in Baltimore, Maryland. Psychol Med. 2001;31(7):1181-91.

6. Suominen K, Isometsä E, Suokas J, Haukka J, Achte K, Lönnqvist J. Completed suicide after a suicide attempt: a 37-year followup study. Am J Psychiatry. 2004;161(3):562-3.

7. Goldney RD, Fisher LJ, Wilson DH, Cheok F. Suicidal ideation and health-related quality of life in the community. Med J Aust. $2001 ; 175(10): 546-9$.

8. Pirkis JE, Burgess PM, Meadows GN, Dunt DR. Suicidal ideation and suicide attempts as predictors of mental health service use. Med J Aust. 2001;175(10):542-5

9. Estimativas a partir da Base de Informações por Setor Censitário. Censo Demográfico 2000 [sítio na Internet]. São Paulo: Fundação IBGE; [citada citada 2004 Mar 19]. Disponível em: URL: http://www.datasus.org.br.

10. César CLG, Carandina L, Alves MCGP, Barros MBA, Goldbaum M. Inquérito de Saúde no Estado de São Paulo (ISA-SP). São Paulo: FAPESP; 1998. [processo 14099-7].

11. Kerkhof A, Bernasco W, Bille-Brahe U, Platt S, Schmidtke A. WHO/EURO Multicentre Study on Parasuicide: European Parasuicide Study Interview Schedule (EPSIS). Leiden: Leiden 
University Department of Clinical Health and Personality Psychology; 1989.

12. Harding TW, Climent CE, Diop M, Giel R, Ibrahim HH, Murthy RS, et al. The WHO collaborative study on strategies for extending mental health care, II: The development of new research methods. Am J Psychiatry. 1983;140(11):1474-80.

13. Mari JJ, Williams P. A validity study of a psychiatric screening questionnaire (SRQ-20) in primary care in the city of Sao Paulo. Br J Psychiatry. 1986;148:23-6.

14. Barbor TF, La Fuente JR, Saunders J, Grant M. AUDIT - The Alcohol Use Disorders Identification Test: Guidelines for use in primary Health Care. Geneva: WHO; 1992.

15. Figlie NB, Pillon SC, Laranjeira RR, Dunn J. Audit identifica a necessidade de interconsulta específica para dependentes de álcool no hospital geral? J Bras Psiquiatr. 1997;46(11):589-93.

16. Weissman MM, Bland RC, Canino GJ, Greenwald S, Hwu HG, Joyce PR, et al. Prevalence of suicide ideation and suicide attempts in nine countries. Psychol Med. 1999;29(1):9-17.

17. Kjoller M, Helweg-Larsen M. Suicidal ideation and suicide attempts among adult Danes. Scand J Public Health. 2000;28(1):54-61.

18. Renberg ES. Self-reported life-weariness, death-wishes, suicidal ideation, suicidal plans and suicide attempts in general population surveys in the north of Sweden 1986 and 1996. Soc Psychiatry Psychiatr Epidemiol. 2001;36(9):429-36.

19. Hintikka J, Pesonen T, Saarinen P, Tanskanen A, Lehtonen J, Viinamaki H. Suicidal ideation in the Finnish general population. A 12-month follow-up study. Soc Psychiatry Psychiatr Epidemiol. 2001;36(12):590-4.

20. Barros MBA, Oliveira HB, Marin-León L. Epidemiologia no Brasil. In: Welang BG, Botega NJ, editors. Comportamento suicida. Porto Alegre: Artmed; 2004. p. 45-58.

21. Federação Espírita Brasileira. O Espiritismo de A a Z. Rio de Janeiro: FEB;1995.

22. Rolim FC. Pentecostais no Brasil: Uma interpretação sócioreligiosa. Petrópolis: Vozes; 1985.

23. Bille-Brahe U. Sociology and suicidal behaviour. In: Hawton K, Heeringen $\mathrm{K}$, editors. The international handbook of suicide and attempted suicide. Chichester: John Wyley \& Sons; 2000. p. 193-208.

24. Berlim MT, Mattevi BS, Pavanello DP, Caldieraro MA, Fleck MP, Wingate LR, Joiner TE Jr. Psychache and suicidality in adult mood disordered outpatients in Brazil. Suicide Life Threat Behav. 2003;33(3):242-8 